\title{
Trends and determinants of HIV transmission among men who inject drugs in the Pokhara Valley, Nepal: analysis of cross-sectional studies
}

Sam Hogan ${ }^{1}$, Andrew Page ${ }^{1,2^{*}}$, Felix Ogbo ${ }^{1,2}$, Sameer Dixit ${ }^{3}$, Rajesh Man Rajbhandari ${ }^{3}$, Bir Rawal ${ }^{4}$ and Keshab Deuba, ${ }^{5,6}$

\begin{abstract}
Background: HIV is a major public health issue around the world, especially in developing countries. Although the overall prevalence of HIV in Nepal is relatively low, there are specific sub-populations where the prevalence is far higher than the national average. One of these sub-groups is male people who inject drugs (male PWIDs). In order to understand the reasons for the differences in prevalence, a series of socio-demographic, behavioural and knowledge-based risk factors need to be assessed.

Methods: The study used a series of 7 cross-sectional survey datasets from Pokhara (Nepal), collected between 2003 and 2017 ( $N=2235$ ) to investigate trends in HIV prevalence among male PWIDs by socio-demographic and behavioural and knowledge-based risk factors. A series of logistic regression models were conducted to investigate the association between study factors and HIV.

Results: HIV prevalence decreased from the levels seen in 2003 (22.0\%) and 2005 (21.7\%), with the lowest prevalence recorded in 2015 (2.6\%), however prevalence has increased in the most recent period (4.9\%). A lower risk of HIV was associated with younger age ( $<=24$ years compared to $>24$ years, $\mathrm{OR}=0.17,95 \% \mathrm{Cl}=0.10-0.31$ ), being married ( $\mathrm{OR}=1.91,95 \% \mathrm{Cl}=1.25-3.02)$ and shorter duration of drug use ( $<=4$ years compared to $>4$ years, $\mathrm{OR}=0.16,95 \% \mathrm{Cl}=0.09-0.29$ ). A higher risk of HIV was associated with low (compared to secondary or higher) education level $(\mathrm{OR}=2.76,95 \% \mathrm{Cl}=1.75-4.36)$, a lack of addiction treatment $(\mathrm{OR}=2.59,95 \% \mathrm{Cl}=1.64-4.08)$, and recent use of unsterilized injection equipment ( $\mathrm{OR}=2.22,95 \% \mathrm{Cl}=1.20-4.11)$.

Conclusion: The prevalence of HIV in male PWIDs in Pokhara has been variable, but overall has reduced in recent years to $2.6 \%$ before increasing in 2017 to $4.9 \%$. The main determinants which increase the risk of HIV among male PWIDs in Pokhara are low education level, a lack of treatment for drug addiction and the recent use of unsterilised equipment. Each of these indicate the need to improve addiction treatment and education programs for intravenous drug use to aid this key population in avoiding risk-taking behaviours.
\end{abstract}

Keywords: Trends, Determinants, Drug use, Behavioural, Male, Nepal

\footnotetext{
* Correspondence: a.page@westernsydney.edu.au

${ }^{1}$ Translational Health Research Institute, Western Sydney University Sydney, Locked Bag 1797, Penrith, NSW 2751, Australia

${ }^{2}$ School of Medicine, Western Sydney University, Sydney, New South Wales, Australia

Full list of author information is available at the end of the article
}

(c) The Author(s). 2021 Open Access This article is licensed under a Creative Commons Attribution 4.0 International License, which permits use, sharing, adaptation, distribution and reproduction in any medium or format, as long as you give appropriate credit to the original author(s) and the source, provide a link to the Creative Commons licence, and indicate if changes were made. The images or other third party material in this article are included in the article's Creative Commons licence, unless indicated otherwise in a credit line to the material. If material is not included in the article's Creative Commons licence and your intended use is not permitted by statutory regulation or exceeds the permitted use, you will need to obtain permission directly from the copyright holder. To view a copy of this licence, visit http://creativecommons.org/licenses/by/4.0/ The Creative Commons Public Domain Dedication waiver (http://creativecommons.org/publicdomain/zero/1.0/) applies to the data made available in this article, unless otherwise stated in a credit line to the data. 


\section{Background}

The spread of human immunodeficiency virus (HIV) among key populations is an important health issue around the world [1]. Several factors have been shown to increased HIV transmission in many communities worldwide. These include safe sex practices, needle sharing habits, intravenous drug use, poor equipment cleaning practices and alcohol consumption [2-4]. Stigma, discrimination and misinformation also play important roles in HIV transmission as they prevent correct dissemination of appropriate information and implementation of preventive methods $[5,6]$.

In Nepal, there are many key populations in some specific locations (the Pokhara Valley and Kathmandu), with a high number of factors which increase the risk of disease transmission like increased economic activities, unsafe sexual practices, and increased levels of drug use [7-16]. These key populations include people who inject drugs, female sex workers, men who have sex with men and labour migrants [17]. These groups are at particularly high risk of contracting HIV and other blood borne diseases such as hepatitis C infection [18]. Without routine testing being readily available and accessible or community-based education on the risks of HIV transmission, there is an increased likelihood of HIV disease burden throughout the community [13].

Previous studies from Nepal have determined the incidence and prevalence of HIV among the key populations to provide relevant data for targeted interventions $[8,11$, $12,14]$. However, those studies focused on specific geographical areas, such as Kathmandu or administrative Development regions of the country, and have not focussed on others where there are higher levels of risks and determinants of HIV transmission, such as the Pokhara valley [17]. The Pokhara valley contains the capital city of Gandaki Province, and is considered to be the tourism capital of Nepal due to its proximity to the Himalayas. The city of Pokhara forms a major tourism and manufacturing hub within Nepal and had an estimated population of approximately 523,000 in 2020. As this city is a major population centre, and the 2nd largest in Nepal, it is important to evaluate the risk factors of HIV within this setting.

While Nepal is considered to be a low prevalence population [19], monitoring and evaluating the HIV epidemiology in specific high-risk locations is still an important public health priority [17]. Public health surveillance programs for HIV has also been recognised as an issue in Nepal [19].

In a recent paper, it was determined that condom adherence is more strongly associated with socio-demographic features, such as socio-economic status, than factors such as education level or knowledge of HIV [20]. This could indicate that sexual health education programs are not currently working as effectively as necessary. Caste and ethnicity also act as major determinants of overall health literacy and knowledge of preventative measures [21]. Injecting drugs at any point within a year has been shown to be a risk factor for non-utilisation of HIV testing centres [22], meaning that the study population are less likely to access these HIV preventative measures than other key populations.

There has been previous descriptive research in the Kathmandu Valley in Nepal into key risk factors and prevalence trends [7-9, 17], however, more detailed analytic approaches to investigate socio-demographic and behavioural factors are currently lacking for this setting. Previous behavioural studies have also shown that there are multiple risk factors that act as determinants for HIV and other sexually transmitted diseases within other areas of Nepal $[10,11]$, such as social class and education level [21]. Accordingly, this study aimed to investigate trends and the associations between socio-demographic, behavioural and knowledge-based factors and HIV transmission among male injection drug users (IDUs) in the Pokhara valley, Nepal from 2003 to 2017. This would provide a more detailed perspective of HIV information among this cohort to inform policy and prevention strategies.

\section{Methods}

The Integrated Biological Behavioural Surveys (IBBS) are a series of surveys taken once every two years in Nepal, beginning in 2003. There have been 7 iterations of this survey. The surveys are intended to track the prevalence of various diseases among targeted populations, in this case men who inject drugs. In addition to assessing disease prevalence, the surveys recorded demographic, behavioural and social factors as part of the surveillance of HIV in Nepal [17]. The key populations that the IBBS focus on are people who inject drugs (PWIDs), labour migrants, sex workers spouses and men who have sex with men [17].

\section{Study sample}

This study uses a series of behavioural surveys taken between 2003 and 2011 and 2015-2017. The total number of participants across this period was 2235 men over the age of 16 who had been injecting drugs for a period of at least three months. Participants were recruited using respondent driven sampling methods, where seeds from the specific target population of men who inject drugs were selected. A full description of the selection and sampling methods are available in the IBBS [17]. The 2003, 2005, 2007 and 2009 surveys all had 300 participants, while the 2011, 2015 and 2017 surveys each had 345.

Face-to-face interviews were performed with participants' answers being recorded on a set questionnaire, with the 2017 survey being performed on tablets. The 
IBBS surveys recorded a wide array of variables, a selection of which were used in the present study (a full list of which is available at the end of each IBBS survey). HIV testing was performed using the Determine HIV $1 /$ 2 test (manufactured by Abbot, Japan), which detects the presence of antibodies against HIV. If this first test produced a positive result, a second and third test were used for confirmation. These tests were Uni-Gold (Trinity Biotech, Ireland) and Stat-Pak HIV 1/2 (Chembio Diagnostics). The third test was only used if there was a disagreement between the first two tests used. If the first test was negative, then no further testing was done. The full testing algorithm is available in the IBBS reports [17], and also shown in Fig. 1. In the 2017 IBBS study, the WHO HIV testing strategy was used. This involved using three consecutive reactive tests as the basis for HIV positive diagnoses. Stat-Pak HIV1/2 was the mandatory kit to confirm any HIV positive diagnoses.

\section{Outcome}

The main outcome of interest in this study was HIV infection. This was defined by use of two rapid detection kits and collected from participants by testing blood samples. The tests were used in a cascading series, where if the first test returned a positive result, the second test would be used to confirm or contradict this result [17]. Cases were determined to be HIV positive only if all three tests showed the blood sample to be reactive. The testing cascade differed in the earlier surveys (2003-2011) so that positives were counted either if the first and second tests were both positive. This difference was due to the different testing kits used from 2003 to 11 .

\section{Risk factors}

Socio-demographic factors included age, education, and marital status, which were all defined as binary variables to maximise the size of comparator groups given the small sample size available at each time-period. Age was defined as being either "above" or "below" the median age. Similarly, education status was defined as being "primary or lower school education" and "secondary or higher school education", while marital status was categorised as a "married" or "not married". Living situation, which was defined as living "with" or "without" a sexual partner was also included in socio-demographic factors.

Behavioural factors included having undergone treatment for drug addiction, being tested for HIV, visiting an HIV testing and counselling centre, duration of intravenous drug use, use of a female sex worker, needle sharing behaviours, alcohol intake, condom use, use of unsterilized injecting equipment and the age at which drugs were first injected. Most of these factors were binary "yes" or "no" variables. Duration of drug use and

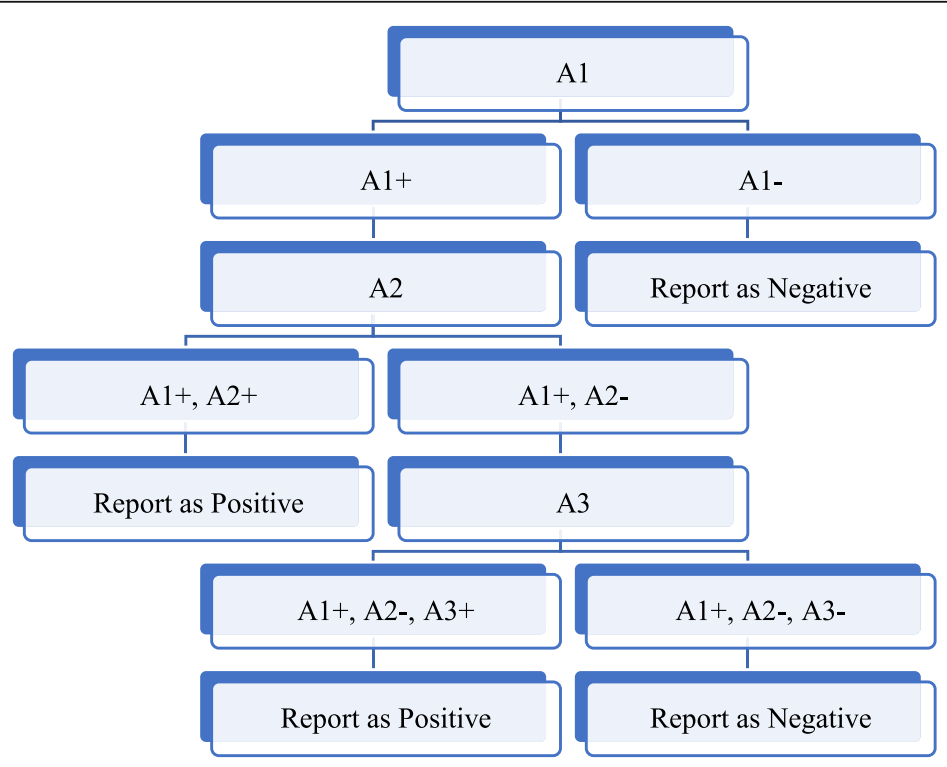

\begin{tabular}{lll}
\hline & Reference Note \\
\hline A1 (First test): & $\rightarrow$ Determine HIV 1/2 \\
A2 (Second test): & $\rightarrow$ Uni-Gold HIV \\
A3 (Third test): & $\rightarrow$ Stat Pak \\
"+" & $\rightarrow$ Reactive \\
"_" & $\rightarrow$ Non-reactive
\end{tabular}

Fig. 1 Testing cascade for the rapid HIV diagnostic tests prior to 2017. Source: IBBS 2015 Report 
age at first injection were defined as being "above" or "below" the median, while alcohol intake was broken into "everyday", "sometimes" and "never".

\section{Participant characteristics}

Overall, the average age of male PWIDs interviewed between 2003 and 2017 increased. The lowest average age occurred in the 2003 survey (average age of 23.4 years), and generally increased with each iteration of the survey. Average age decreased slightly between 2007 and 2009 (24.8 to 24.5 years), before increasing in 2011 (24.9 years). The highest average age occurred in the 2017 (28.2 years).

The education status of the respondents increased every year between 2003 and 2015, before decreasing in 2017. The highest completed grade of school on average in the surveys occurred in 2011 and 2015 (Grade 9). The average highest completed grade in 2003 was Grade 7, before increasing to Grade 8 in all other years.

Factors relating to knowledge of HIV included knowing someone with HIV/AIDS, having met and discussed HIV with a peer/community educator (PE/CE), and knowledge of where to access antiretroviral therapy.

A summary of participant characteristics is provided in Supplementary Table 1.

\section{Analysis}

Prevalence estimates and 95\% confidence intervals for HIV were examined over the period spanning 2007-2017, stratified by each of the study variables described above.

A separate series of logistic regression models that were restricted to the period 2007 to 2017 were also conducted. Models were restricted to this period because the prevalence numbers expressed in 2003 and 2005 were likely substantially affected by measurement bias. This was due to overestimation of the positive results, which may have been due to a change in the HIV testing regime and the definition of a positive case. In these years, HIV testing was performed using two rapid tests ("Capillus" and "Determine"), with disagreements being resolved with the use of "Uni-Gold TM".

Univariable and multivariable logistic regression models were conducted to investigate the association between the socio-demographic, behavioural and knowledge factors described above and HIV status. Models were aggregated over the period 2007-2017. Additionally, single years were investigated to evaluate the magnitude of change of relative associations between different time points. Multivariable models adjusted for the potential confounding factors of age, education level and marital status. Multivariable models adjusted for the key potential confounding factors of age, education level and marital status. Knowledge, behavioural and health service determinants were considered for inclusion in multivariable models, however given small numbers of cases within strata for some variables and the cross-sectional data used, the putative causal directions between these variables could not be clearly specified, therefore a minimal set of socio-demographic factors were adjusted for. All analyses were conducted in R Studio using the glm and confint.lm functions, which produced the estimates for odds ratios and 95\% confidence intervals for each of these models.

\section{Results}

HIV prevalence decreased over the study period 2003 to 2015 from 22 to $2.6 \%$ before rising again in 2017 to $4.9 \%$ (Table 1). The lowest prevalence for HIV in the study populations occurred in 2015 (2.6 95\% CI 1.2-4.9\%), however prevalence has increased in the most recent period in 2017 numbers (4.9, 95\% CI 2.9-7.8\%). There was a decrease in every survey prior to 2017 , with the largest decrease occurring between 2005 (21, 95\% CI 17.1-26.8\%) and 2007 (8.6, 95\% CI 5.7-12.4\%). HIV prevalence was higher among participants who were above the median age in all years, and was also lower in participants who had achieved secondary education or higher in all years except for 2003 (Table 1.) Having injected with a used syringe in the previous week had a higher prevalence of HIV in all years except for 2015 (Table 2). HIV prevalence was higher among participants who had received treatment for drug addiction in all years (Table 3). Individuals who knew others with HIV/AIDS and knew where to receive ART also had a higher prevalence of HIV (Table 3.).

Lower risk of HIV was associated with an education level of secondary school or higher $(\mathrm{OR}=0.36,95 \% \mathrm{CI}=$ $0.23,0.57)$, marital status $(\mathrm{OR}=0.51,95 \% \mathrm{CI}=0.33$, $0.80)$, having never received addiction treatment $(\mathrm{OR}=$ $0.39,95 \% \mathrm{CI}=0.25,0.61$ ), not having discussed with $\mathrm{PE} /$ $\mathrm{CE} \quad(\mathrm{OR}=0.55,95 \% \mathrm{CI}=0.32,0.96)$ and not having knowledge of ART $(\mathrm{OR}=0.21,95 \% \mathrm{CI}=0.13,0.33)$ (Tables 4 and 5). In addition to this, not having had sex with a FSW in the past year was also protective, however had a statistically insignificant confidence interval.

A higher risk of HIV was associated with being above the median age of $24(\mathrm{OR}=5.75,95 \% \mathrm{CI}=3.19,10.36)$ and having injected drugs for more than the median duration of 4 years $(\mathrm{OR}=6.94,95 \% \mathrm{CI}=3.91,12.31)$ (Table 5.). Not using a condom with an FSW and first injecting later than the median age of 20 years old were also associated with higher risk of HIV prevalence, although differences were not statistically significant (Table 5.).

\section{Discussion}

The overall prevalence of HIV among male PWIDs in the Pokhara valley varied across the study period examined in this study. In 2003 and 2005, the prevalence was 


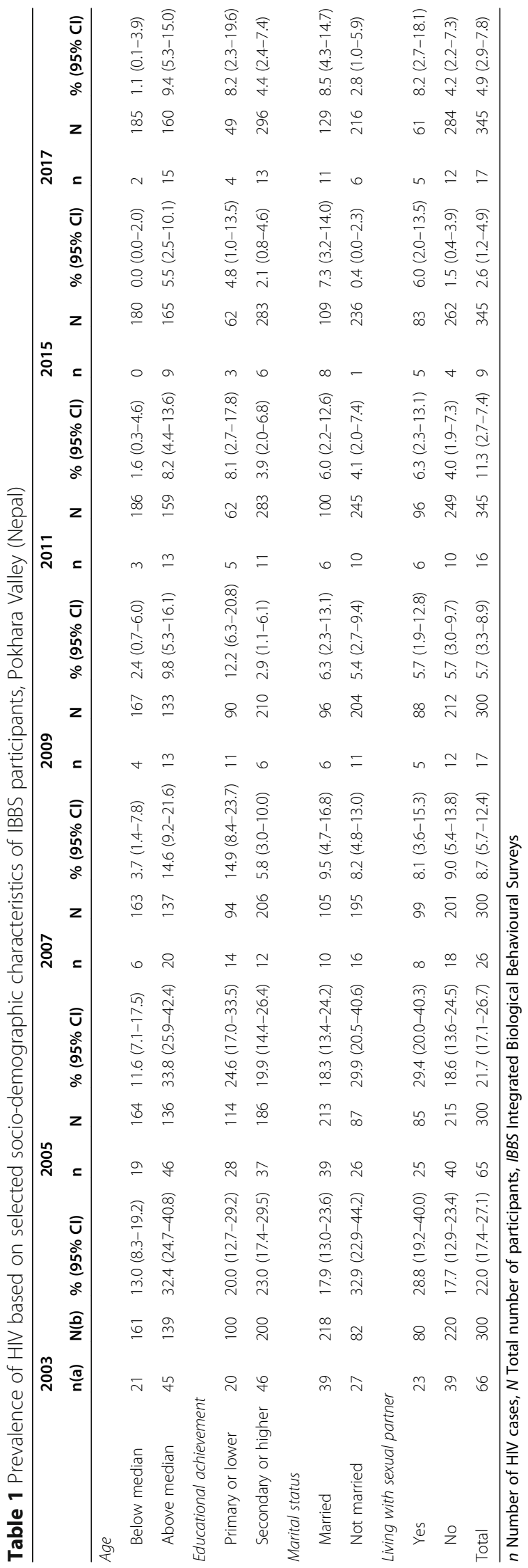




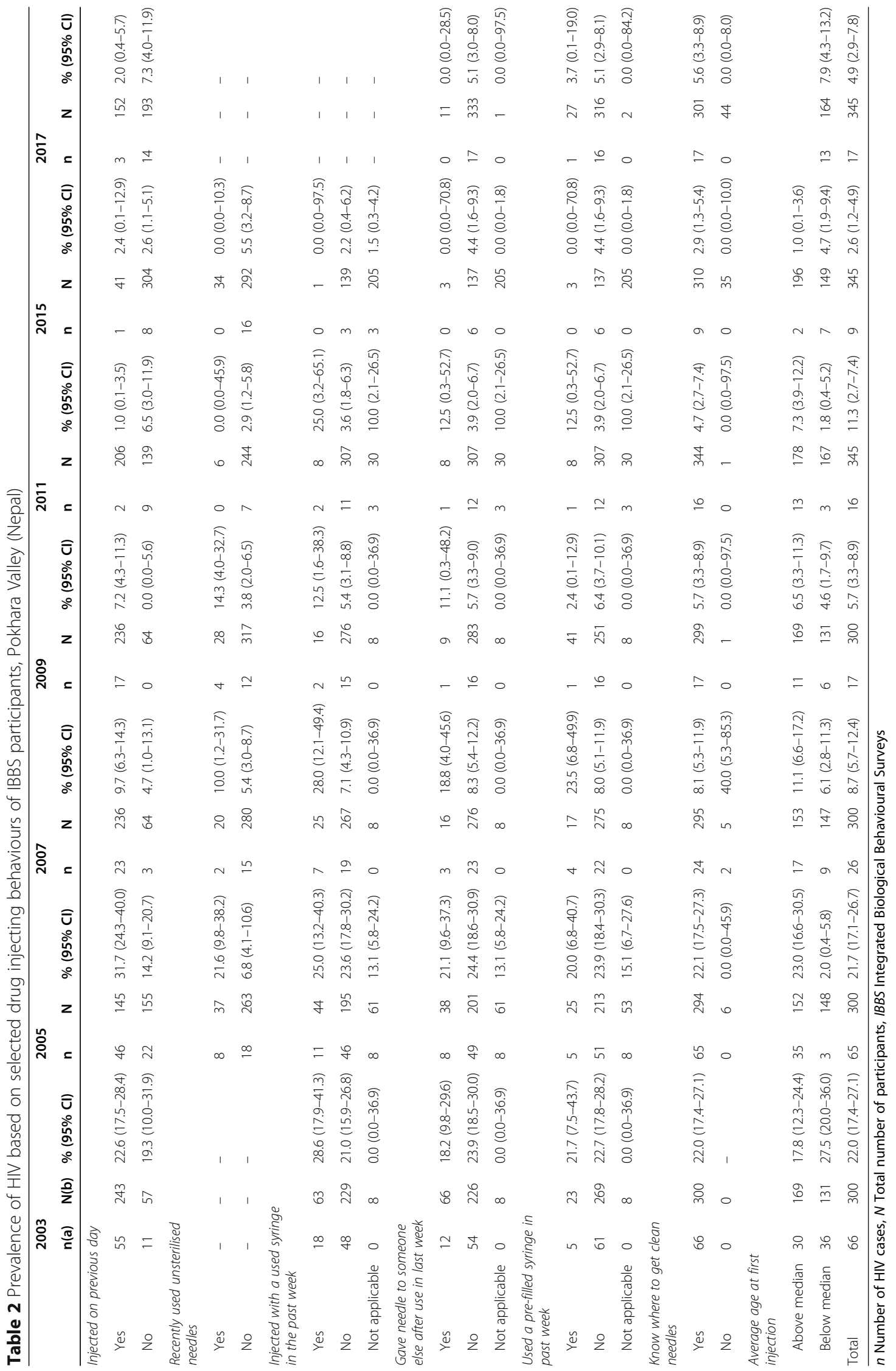




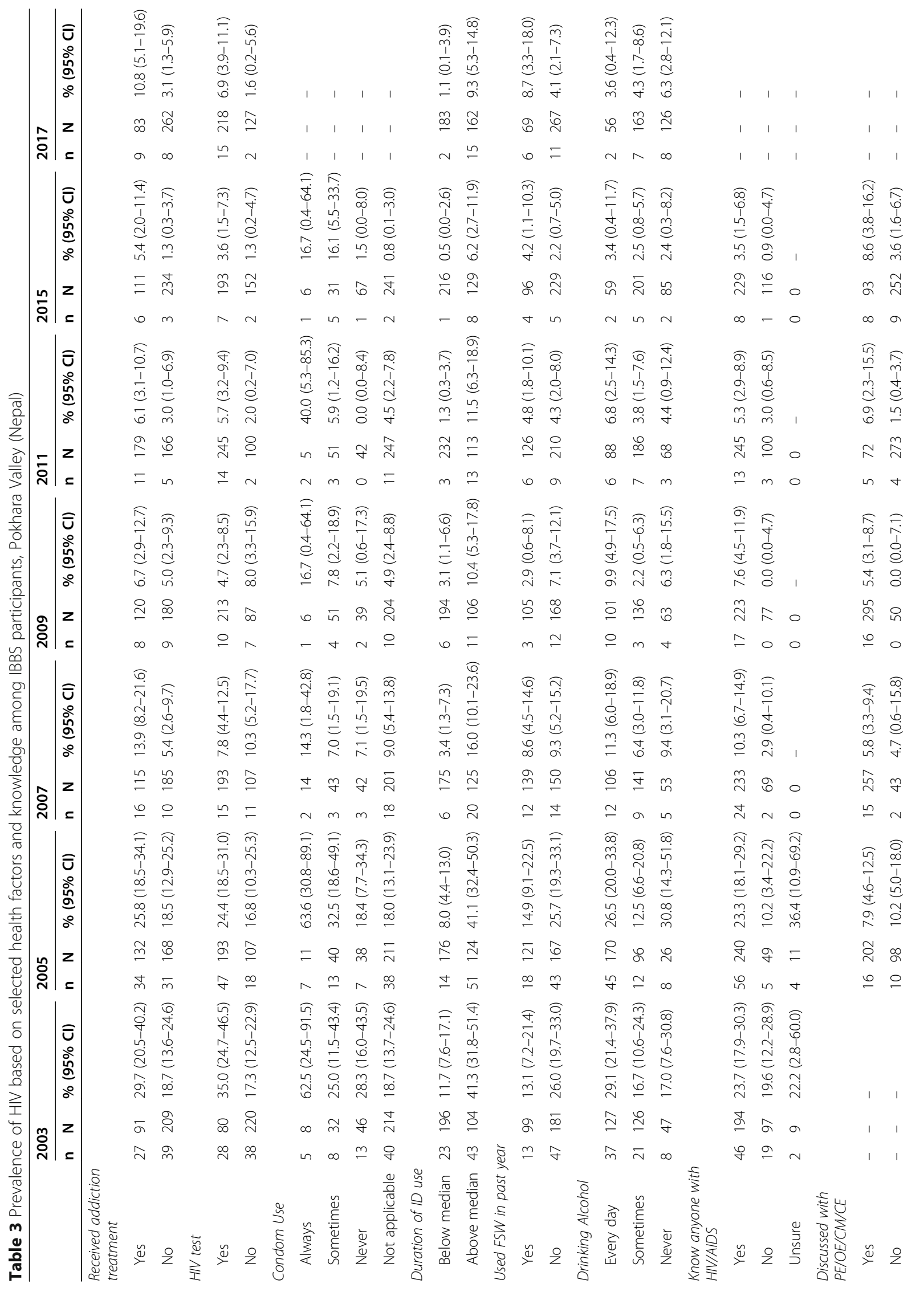




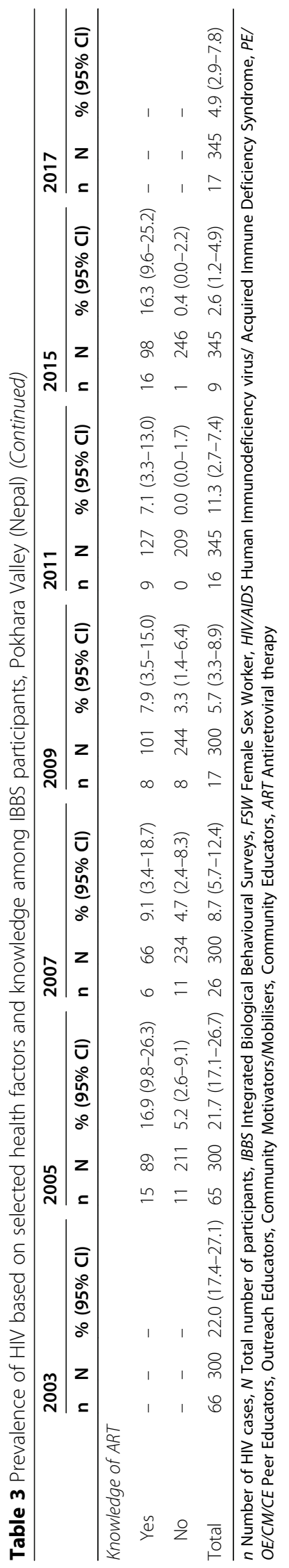


Table 4 Socio-demographic determinants of HIV Prevalence among male injecting drug users, Pokhara Valley (Nepal)

\begin{tabular}{|c|c|c|c|c|c|c|}
\hline & \multicolumn{6}{|l|}{ OR $(95 \% \mathrm{Cl})$} \\
\hline & 2007 & 2009 & 2011 & 2015 & 2017 & 2007-2017 \\
\hline \multicolumn{7}{|l|}{ Socio-demographic Factors } \\
\hline \multicolumn{7}{|l|}{ Age } \\
\hline Below Median Age & 1.00 & 1.00 & 1.00 & - & 1.00 & 1.00 \\
\hline Above Median Age & $4.47(1.73-11.53)$ & $4.41(1.40-13.94)$ & $5.43(1.51-19.50)$ & - & $9.47(2.12-42.48)$ & $5.75(3.19-10.36)$ \\
\hline \multicolumn{7}{|c|}{ Educational achievement Status } \\
\hline Primary or lower & 1.00 & 1.00 & 1.00 & 1.00 & 1.00 & 1.00 \\
\hline Secondary or higher & $0.35(0.16-0.80)$ & $0.21(0.08-0.59)$ & $0.46(0.15-1.38)$ & $0.43(0.10-1.76)$ & $0.52(0.16-1.66)$ & $0.36(0.23-0.57)$ \\
\hline \multicolumn{7}{|l|}{ Marital Status } \\
\hline Not married & 1.00 & 1.00 & 1.00 & 1.00 & 1.00 & 1.00 \\
\hline Married & $1.15(0.51-2.71)$ & $1.17(0.42-3.28)$ & $1.50(0.53-4.26)$ & $18.62(2.28-151.90)$ & $3.26(1.17-9.08)$ & $1.94(1.25-3.02)$ \\
\hline \multicolumn{7}{|c|}{ Living with sexual partner situation } \\
\hline Yes & 1.00 & 1.00 & 1.00 & 1.00 & 1.00 & 1.00 \\
\hline No & $1.12(0.47-2.68)$ & $1(0.34-2.93)$ & $0.63(0.22-1.78)$ & $0.24(0.06-0.93)$ & $0.49(0.17-1.46)$ & $0.70(0.44-1.13)$ \\
\hline
\end{tabular}

recorded as 22.0 and $21.7 \%$, before declining to $8.7 \%$ in 2007 and $5.7 \%$ in 2009 . There was an increase in 2011 to $11.3 \%$, before a marked decline in 2015 to $2.6 \%$. In the most recent survey at the time of this study, the prevalence recorded for 2017 was 4.9\%, indicating that although lower than the 2011 measurement, the prevalence of HIV among male PWIDs increased in the most recent period.

The findings in this study indicate that the main behavioural determinants of HIV among male PWIDs in the Pokhara valley are use of unsterilized needles, a lower level of education and high alcohol intake. Low alcohol use and not having sexual intercourse with female sex workers in the last year were both associated with a lower risk of HIV, although the association was statistically insignificant. It was found that having an education level of secondary school or higher, not being married, having never received addiction treatment, not having discussed with PE/CE and not having knowledge of ART were all associated with lower risk of HIV.

Findings also indicate that the number of IDUs who had ever received treatment for their addiction has decreased since 2007. However, daily alcohol consumption and use of female sex workers decreased over the study period, which occurred contemporaneously with the decline in HIV prevalence from 2007 onwards. In the most recent survey, the decrease in alcohol consumption is potentially due to changes in government regulations on alcohol [23]. Analysis of the prevalence of different behaviours indicated that frequency of the majority of needle sharing behaviours also decreased. Education status was not consistently significant in either the unadjusted or adjusted models, although individual years produced statistically significant ORs. One study based on drug use in third-year medical students in Kathmandu noted that most respondents reported that they only began using drugs after admission to medical school [24]. This potentially indicates that drug use is closely associated with education levels.

Younger age was found to be associated with a lower risk of HIV in all models, which is consistent with previous findings $[25,26]$. There are slight differences in the magnitude of the observed association, however this may have been due to the differences in classification when creating a dichotomous age category. Similarly, not being married was associated with lower risk of HIV in several of the models from this study.

Recent use of unsterilized injection equipment was predictably a risk factor for HIV status in the 2007-2017 models, although was not consistently statistically significant. This may be due to a variety of factors, such as difference in cleaning methods or the effect of the demographic confounders being adjusted for. Unsterilized or contaminated equipment has been shown to be a risk factor in multiple different settings $[4,8,27,28]$. This problem is likely to be exacerbated by the low coverage of programs aimed at providing PWIDs with clean injecting equipment. Data from 2016 shows that the current rate of distribution of clean needles is far lower than the recommended standard of at least 200 per PWID per year [29]. 
Table 5 Knowledge, behavioural and health service determinants of HIV among male injecting drug users, Pokhara Valley (Nepal)

\begin{tabular}{|c|c|c|c|c|c|c|}
\hline & \multicolumn{6}{|l|}{ OR $(95 \% \mathrm{Cl})$} \\
\hline & 2007 & 2009 & 2011 & 2015 & 2017 & 2007-2017 \\
\hline \multicolumn{7}{|c|}{ Recent use of unsterilised needles } \\
\hline Yes & 1.00 & 1.00 & 1.00 & - & - & 1.00 \\
\hline No & $0.27(0.11-0.67)$ & $0.63(0.23-1.68)$ & $0.24(0.07-0.79)$ & - & - & $0.45(0.24-0.83)$ \\
\hline \multicolumn{7}{|c|}{ Avoids needle sharing behaviour } \\
\hline No & 1.00 & 1.00 & 1.00 & - & - & 1.00 \\
\hline Yes & $0.13(0.04-0.48)$ & $0.38(0.05-3.03)$ & $0.07(0.01-0.75)$ & - & - & $0.54(0.20-1.41)$ \\
\hline \multicolumn{7}{|l|}{ Age at first injection } \\
\hline Below median & 1.00 & 1.00 & 1.00 & 1.00 & 1.00 & 1.00 \\
\hline Above median & $0.52(0.22-1.22)$ & $0.73(0.25-1.92)$ & $0.23(0.06-0.83)$ & $4.78(0.97-23.49)$ & $3.81(1.21-11.98)$ & $1.06(0.68-1.66)$ \\
\hline \multicolumn{7}{|c|}{ Received addiction treatment } \\
\hline Yes & 1.00 & 1.00 & 1.00 & 1.00 & 1.00 & 1.00 \\
\hline No & $0.35(0.15-0.81)$ & $0.74(0.27-1.97)$ & $0.47(0.16-1.40)$ & $0.23(0.06-0.93)$ & $0.26(0.10-0.70)$ & $0.39(0.25-0.61)$ \\
\hline \multicolumn{7}{|l|}{ HIV test } \\
\hline Yes & 1.00 & 1.00 & 1.00 & 1.00 & - & 1.00 \\
\hline No & $1.36(0.60-3.09)$ & $1.78(0.65-4.85)$ & $0.34(0.07-1.52)$ & $0.35(0.07-1.74)$ & - & $0.74(0.46-1.21)$ \\
\hline \multicolumn{7}{|c|}{ Condom use (past 12 months) } \\
\hline Always & 1.00 & 1.00 & - & 1.00 & - & 1.00 \\
\hline Never & $0.46(0.07-3.12)$ & $0.27(0.02-3.59)$ & - & $0.08(0.01-1.45)$ & - & $1.35(0.57-3.20)$ \\
\hline \multicolumn{7}{|l|}{ Duration of ID use } \\
\hline Below median & 1.00 & 1.00 & 1.00 & 1.00 & 1.00 & 1.00 \\
\hline Above median & $5.37(2.08-13.85)$ & $3.63(1.30-10.15)$ & $9.92(2.75-35.75)$ & $14.21(1.74-115.87)$ & $9.23(2.07-41.25)$ & $6.94(3.91-12.31)$ \\
\hline \multicolumn{7}{|c|}{ Use of FSW (past 12 months) } \\
\hline Yes & 1.00 & 1.00 & 1.00 & 1.00 & 1.00 & 1.00 \\
\hline No & $1.09(0.48-2.45)$ & $2.43(0.67-8.86)$ & $0.90(0.31-2.59)$ & $0.51(0.13-1.96)$ & $0.45(0.16-1.27)$ & $0.93(0.58-1.48)$ \\
\hline \multicolumn{7}{|c|}{ Alcohol use (past 12 months) } \\
\hline Yes & 1.00 & 1.00 & 1.00 & 1.00 & 1.00 & 1.00 \\
\hline No & $0.82(0.27-2.46)$ & $0.62(0.18-2.07)$ & $0.60(0.14-2.51)$ & $0.69(0.09-5.05)$ & $1.83(0.37-8.87)$ & $0.80(0.45-1.41)$ \\
\hline \multicolumn{7}{|c|}{ Discussed with PE/OE/CM/CE } \\
\hline Yes & 1.00 & 1.00 & & 1.00 & 1.00 & 1.00 \\
\hline No & $1.32(0.57-3.04)$ & $0.79(0.17-3.59)$ & & $0.20(0.05-0.77)$ & $0.39(0.15-1.06)$ & $0.55(0.32-0.96)$ \\
\hline \multicolumn{7}{|c|}{ Knowledge of where to get ART } \\
\hline Yes & 1.00 & 1.00 & 1.00 & - & 1.00 & 1.00 \\
\hline No & $0.27(0.12-0.62)$ & $0.49(0.17-1.39)$ & $0.39(0.14-1.08)$ & - & $0.02(0.01-0.16)$ & $0.21(0.13-0.33)$ \\
\hline
\end{tabular}

ID Injection drugs, FSW Female sex worker, PE/OE/CM/CE Peer Educators, Outreach Educators, Community Motivators/Mobilisers, Community Educators, Antiretroviral therapy.

Logistic regression models were run on the combined datasets from 2007 to 2017 with year being adjusted for as a confounder. The models examined sociodemographic factors and whether these acted as determinants of HIV status over the period of 2007-2017. The 2003 and 2005 datasets were excluded from this analysis as the inflated prevalence of HIV in those years would have skewed the results. Some variables presented in Tables 1-3 were excluded from models due to small case numbers and unstable estimates. Models are adjusted for age, education level and marital status

In general, HIV knowledge was high among the participants of the surveys. Most of the participants knew someone with HIV/AIDS, and most had what was determined by the DHS standards as a "comprehensive knowledge of HIV". The number of individuals with comprehensive knowledge increased from 2015 to 2017, suggesting better engagement in HIV education services in male PWIDs. However, the high risk associated with having experienced addiction treatment and using $\mathrm{PE}$ suggests that although the knowledge of HIV was relatively high, health programs may have been accessed insufficiently before the individual knew their HIV status. 
It should also be noted that coverage of these healthcare programs in Nepal is limited, which may be the reason for lower rates of accessing these programs. Issues with service access outside of major population centres and stigma within the general population may have limited the effectiveness of addiction interventions. Reducing stigma around drug use and addiction, as well as HIV, could be a potential strategy to increase access to these programs.

Conversely, knowledge of where to receive antiretroviral therapy reached the lowest number in 2017. Compared to other developing countries, the level of knowledge of HIV in Nepal is encouraging. Data gathered from the DHS (Demographic and Health Surveys) and AIDS Indicator Surveys (AIS) in 33 sub-Saharan countries showed only minimal increases in the level and spread of HIV knowledge between 2003 and 2015 [30].

There are several potential limitations with this study. Most of these relate to the cross-sectional nature of the data, conducted at multiple time points which opens up the potential for small shifts in methodology to affect consistency in measurement over time. In addition to this, some of the data from the 2017 set was missing (including data on knowing someone with HIV), meaning that some risk factors were unable to be properly investigated in this year.

It is also difficult to determine the role of changes in legislation or other HIV specific interventions across the timespan of the IBBS surveys. The difficulties in utilising the findings from IBBS surveys has been noted in the past, with several reasons provided for why the interpretation and implementation of findings is complicated [31]. The difficulties mentioned are also likely to impact the results of the surveys, such as issues with sampling consistency. Some sources of measurement bias are likely to be present in the surveys, as they were conducted by different people across a relatively large time. Additionally, the survey results relied heavily upon the self-reporting of the participants, potentially creating inaccuracies. Selection bias is also possible, as volunteerism means that the IDUs selected for the survey may not have been representative of all IDUs in Pokhara.

Due to the cross-sectional study design, temporality and causality are also difficult to establish. Although the answers for variables may indicate causality, it cannot be ascertained which of the variables came first.

However, there are strengths to the study. For example, analysing the changing risk of different behaviours over time is helpful in determining if health programs are acting effectively in reducing HIV prevalence. HIV diagnoses were not reliant on self-reporting, but were based on biological samples, reducing the likelihood of reporting bias. In addition to this, knowing which behavioural and demographic risk factors are becoming more prevalent in recent years is valuable information for health service programs. Targeted HIV prevention programs have provided encouraging results, both in Nepal [32] and other developing countries [33-35]. Strengthening and tailoring the current HIV programs to better suit the individuals who need them should be a priority moving forward.

Increasing both the knowledge of and access to antiretroviral therapy is also a potential avenue of reducing the spread of HIV, as it has been shown that ART is one of the most effective mechanisms of controlling HIV [36]. The issues with ART adherence and access in Nepal have been noted previously [37]. In the most recent government strategy document related to HIV control, the National HIV Strategy 2016-2021 [29] targets $90 \%$ retention for individuals diagnosed with HIV on ART, while also aiming to identify, test and correctly diagnose $90 \%$ of the key populations [29]. The results found in this paper appear to show that the numbers of IDUs who have been tested for HIV, while increasing, remain below the $90 \%$ target testing rate. Additionally, the numbers of HIV positive individuals in this study who know where and how to get ART were far lower than the target, as only $16 \%$ of those with HIV and only $12 \%$ of IDUs overall knew where to receive this treatment.

\section{Conclusion}

As Pokhara represents one of the largest population centres in Nepal and a hub for tourism, the findings are somewhat representative of many other large population centres within the country. The prevalence of HIV in male PWIDs in Pokhara has been variable, but overall has reduced in recent years reaching $2.6 \%$ before increasing in 2017 to $4.9 \%$. This study has identified several important socio-demographic and modifiable behavioural risk factors associated with trends in HIV prevalence among male PWIDs in Nepal to inform current population health policy strategies and responses. Based on the levels of knowledge of the male PWIDs, addiction treatment and HIV education programs need to be strengthened in future intervention strategies.

\section{Supplementary Information}

The online version contains supplementary material available at https://doi. org/10.1186/s12889-021-10331-9.

Additional file 1: Table S1. Participant characteristics of the Integrated Biological Behavioural Surveys, Pokhara Valley (Nepal).

\section{Abbreviations}

AIDS: Acquired Immune Deficiency Syndrome; AIS: AIDS Indicator Surveys; ART: Antiretroviral Therapy; DHS: Demographic and Health Surveys; FSW: Female Sex Worker; HIV: Human Immunodeficiency Virus; 
IDU: Intravenous Drug User; IBBS: Integrated Biological Behavioural Survey; PE/CE: Peer Educator/Community Educator; PE/OE/CM/CE: Peer Educators/ Outreach Educators/Community Motivators/ Community Educators; PWID: People Who Inject Drugs

\section{Acknowledgements}

Not applicable.

\section{Authors' contributions}

$\mathrm{SH}$ was a major contributor in writing the manuscript and analysing the data sets. AP and SM contributed to writing the manuscript and advised on statistical analysis. FO contributed to writing the manuscript. RR contributed to data acquisition and statistical analysis. BR and KD were major contributors on the design and publication of results from the original IBBS projects. All authors have read and approved the final manuscript. FO is an Associate Editor of this journal.

\section{Funding}

SD received a grant paid to CMDN by the Global Fund via the Nepal Government, relating to this work. This funding is no longer current. No other authors received funding for this project.

\section{Availability of data and materials}

The datasets used and/or analysed during the current study are available from the corresponding author on reasonable request. CMDN maintain the individual datasets from IBBS studies, with information on each IBBS study available here: http://library.nhrc.gov.np:8080/nhrc/handle/123456789/18/ search

\section{Ethics approval and consent to participate}

The original ethics approval granted to the IBBS projects in Nepal was given by the Nepal Health Research Council (NHRC). The survey was conducted in compliance with all human rights and ethical standards required by health researchers conducting studies on human subjects.

Both verbal and written informed consent was obtained from individuals before the interview process in the survey, in the presence of a witness who then signed the consent form. Verbal witnessed consent was obtained for those participants who were illiterate, with this method of consent being approved by the NHRC. The surveys did not record personal identifiers, with an aim to maintain privacy and anonymity. Participants were provided with opportunities to ask questions during the screening process to help aid their decision to participate or decline to participate. Additionally, potential participants were made aware that they were able to freely decline involvement during any stage of the survey. Risk to individuals was minimal, and best efforts to maintain the minimal risk. During analysis and presentation of the survey findings, names and addresses of participants were not mentioned.

\section{Consent for publication}

Not applicable.

\section{Competing interests}

FO has a conflict of interest as they are an editor for this journal. The other authors have no competing interests.

\section{Author details}

${ }^{1}$ Translational Health Research Institute, Western Sydney University Sydney, Locked Bag 1797, Penrith, NSW 2751, Australia. ${ }^{2}$ School of Medicine, Western Sydney University, Sydney, New South Wales, Australia. ${ }^{3}$ Center For Molecular Dynamics, Kathmandu, Nepal. ${ }^{4}$ National Center for AIDS and STD Control, Kathmandu, Nepal. ${ }^{5}$ Department of Global Public Health, Karolinska Institutet, Stockholm, Sweden. ${ }^{6}$ National Centre for AIDS \& STD Control/ Global Fund Programs, Kathmandu, Nepal.

Received: 11 February 2020 Accepted: 25 January 2021 Published online: 02 February 2021

\section{References}

1. WHO. Global Health Observatory Data - HIV/AIDS WHO website. 2017. Available from: http://www.who.int/gho/hiv/en/.
2. Koblin BA, Husnik MJ, Colfax G, Huang Y, Madison M, Mayer K, et al. Risk factors for HIV infection among men who have sex with men. AIDS. 2006; 20(5):731-9.

3. Zuma K, Gouws E, Williams B, Lurie M. Risk factors for HIV infection among women in Carletonville, South Africa: migration, demography and sexually transmitted diseases. Int J STD AIDS. 2003;14(12):814-7.

4. Neaigus A, Friedman SR, Jose B, Goldstein MF, Curtis R, Ildefonso G, et al. High-risk personal networks and syringe sharing as risk factors for HIV infection among new drug injectors. JAIDS Journal of Acquired Immune Deficiency Syndromes. 1996;11(5):499-509.

5. Cianelli R, Ferrer L, McElmurry BJ. HIV prevention and low-income Chilean women: machismo, marianismo and HIV misconceptions. Culture, Health \& Sexuality. 2008;10(3):297-306.

6. Shrestha S, Shibanuma A, Poudel KC, Nanishi K, Koyama Abe M, Shakya SK, et al. Perceived social support, coping, and stigma on the quality of life of people living with HIV in Nepal: a moderated mediation analysis. AIDS Care. 2018:1-8.

7. Deuba K, Ekström AM, Tomson G, Shrestha R, Marrone G. HIV decline associated with changes in risk behaviours among young key populations in Nepal: analysis of population-based HIV prevalence surveys between 2001 and 2012. Int J STD AIDS. 2016;28(9):864-75.

8. Ghimire B, Suguimoto SP, Zamani S, Ono-Kihara M, Kihara M. Vulnerability to HIV infection among female drug users in Kathmandu Valley, Nepal: a crosssectional study. BMC Public Health. 2013;13(1):1238.

9. Kakchapati S, Gautam N, Kc KP, Rawal BB. HIV awareness and safe sexual behaviors among female sex workers in Kathmandu valley of Nepal. HIV/ AIDS (Auckland, NZ). 2018;10:157-66.

10. Kakchapati S, Maharjan M, Rawal BB, Dixit SM. Social determinants and risk behaviors associated with prevalent hepatitis $\mathrm{C}$ and HIV/HCV co-infection among male injection drug users in Nepal. Archives of Public Health. 2017; 75(1):39.

11. Karmacharya D, Yu D, Dixit S, Rajbhandari R, Subedi B, Shrestha S, et al. A study of the prevalence and risk factors leading to HIV infection among a sample of street children and youth of Kathmandu. AIDS Res Ther. 2012;9(1):25.

12. Nepal B. Population mobility and spread of HIV across the indo-Nepal border. J Health Popul Nutr. 2007;25(3):267-77.

13. Poudel AN, Newlands D, Simkhada P. The economic burden of HIV/AIDS on individuals and households in Nepal: a quantitative study. BMC health services research. 2017;17(1):76-.

14. Poudel K, Okumura J, Sherchand J, Jimba M, Murakami I, Wakai S. Mumbai disease in far western Nepal: HIV infection and syphilis among male migrant-returnees and non-migrants. Trop Med Int Health. 2003;8(10):933-9.

15. Thapa S, Thapa D, Buve A, Hannes K, Nepal C, Mathei C. HIV-related risk Behaviours among labor migrants, their wives and the general population in Nepal. J Community Health. 2017;42(2):206-68.

16. Tsai AC, Weiser SD. Population-based study of food insecurity and HIV transmission risk behaviors and symptoms of sexually transmitted infections among linked couples in Nepal. AIDS Behav. 2014;18(11):2187-97.

17. NCASC. Integrated Biological and Behavioral Surveillance (IBBS) Survey among People Who Inject Drugs (PWID-Male) in Pokhara Valley. 2017.

18. Shrestha A. Viral hepatitis in Nepal: past, present, and future. Euroasian journal of hepato-gastroenterology. 2016;6(1):59-61.

19. Paudel T, Singh N, Raj Banjara M, Kafle SP, Chandra Ghimire Y, Pokharel BR, et al. Epidemiology of HIV, programmatic progress and gaps in last 10 years in Nepal. J Virus Erad. 2016;2(Suppl 4):35-40.

20. Sharma B, Nam EW. Condom use at last sexual intercourse and its correlates among males and females aged 15-49 years in Nepal. Int J Environ Res Public Health. 2018;15(3):535.

21. Atteraya $\mathrm{M}, \mathrm{Kimm} \mathrm{H}$, Song $\mathrm{H}$. Caste- and ethnicity-based inequalities in HIV/ AIDS-related knowledge gap: a case of Nepal. Health \& Social Work. 2015; 40(2):100-7.

22. Shrestha R, Philip S, Shewade HD, Rawal B, Deuba K. Why don't key populations access HIV testing and counselling centres in Nepal? Findings based on national surveillance survey. BMJ Open. 2017;7(12):e017408.

23. Internatioal I. Nepal: Government Adopted New Alcohol Law 2017 [updated 22/02/2017]. Available from: http://iogt.org/news/2017/02/22/nepalgovernment-adopted-new-alcohol-law/.

24. Budhathoki N, Shrestha MK, Acharya N, Manandhar A. Subantance Use Among Third year Medical Students of Nepal. Journal of Nepal Health Research Council. 2010. 
25. FHI. Behavioral and Sero-Prevalence Survey Among Injecting Drug Users (IDUs) in Pokhara Valley. New ERA SACTS, 2003.

26. FHI. Integrated Bio-Behaviorual Survey (IBBS) Among Male Injecting Drug Users (IDUs) In Pokhara. New ERA SACTS Family Health International, 2005.

27. Strathdee SA, Stockman JK. Epidemiology of HIV among injecting and noninjecting drug users: current trends and implications for interventions. Current HIV/AIDS Reports. 2010;7(2):99-106.

28. Prevention CfDCa. HIV Infection and HIV-Associated Behaviours Among Injecting Drug Users - 20 Cities, United States, 2009. Morbidity and Mortality Weekly Report. 2012;61(8).

29. National Centre for AIDS and STD Control. National HIV Strategic Plan 20162021. In: Ministry of Health, editor:: Government of Nepal; 2016.

30. Chan BT, Tsai AC. HIV knowledge trends during an era of rapid antiretroviral therapy scale-up: an analysis of 33 sub-Saharan African countries. J Int AIDS Soc. 2018;21(7):e25169.

31. Deuba K, Ojha B, Shrestha R, Ekström AM, Marrone G, Kc NP, et al. Optimizing the implementation of integrated biological and behavioural surveillance surveys of HIV in resource limited settings-lessons from Nepal. Asian Pacific Journal of Tropical Disease. 2014;4:S605-S15.

32. Poudel KC, Buchanan DR, Poudel-Tandukar K. Effects of a community-based HIV risk reduction intervention among HIV-positive individuals: results of a quasi-experimental study in Nepal. AIDS Educ Prev. 2015;27(3):240-56.

33. Berkman A, Garcia J, Muñoz-Laboy M, Paiva V, Parker R. A critical analysis of the Brazilian response to HIV/AIDS: lessons learned for controlling and mitigating the epidemic in developing countries. Am J Public Health. 2005; 95(7):1162-72.

34. Bateganya $\mathrm{MH}$, Dong M, Oguntomilade J, Suraratdecha C. The Impact of Social Services Interventions in Developing Countries: A Review of the Evidence of Impact on Clinical Outcomes in People Living With HIV. Journal of acquired immune deficiency syndromes (1999). 2015;68(0 3):S357-S67.

35. Medley A, Kennedy C, O'Reilly K, Sweat M. Effectiveness of peer education interventions for HIV prevention in developing countries: a systematic review and meta-analysis. AIDS Educ Prev. 2009;21(3):181-206.

36. Vermund SH, Tique JA, Cassell HM, Johnson ME, Ciampa PJ, Audet CM Translation of biomedical prevention strategies for HIV: Prospects and pitfalls. Journal of acquired immune deficiency syndromes (1999). 2013;63(0 1):S12-S25.

37. Bam K, Rajbhandari RM, Karmacharya DB, Dixit SM. Strengthening adherence to anti retroviral therapy (ART) monitoring and support: operation research to identify barriers and facilitators in Nepal. BMC Health Serv Res. 2015;15(1):188.

\section{Publisher's Note}

Springer Nature remains neutral with regard to jurisdictional claims in published maps and institutional affiliations.

Ready to submit your research? Choose BMC and benefit from:

- fast, convenient online submission

- thorough peer review by experienced researchers in your field

- rapid publication on acceptance

- support for research data, including large and complex data types

- gold Open Access which fosters wider collaboration and increased citations

- maximum visibility for your research: over $100 \mathrm{M}$ website views per year

At $\mathrm{BMC}$, research is always in progress.

Learn more biomedcentral.com/submissions 